\title{
BILATERAL HYPERTROPHIC OLIVARY DEGENERATION SECONDARY TO ISCHEMIA FOLLOWING ENDOVASCULAR TREATMENT OF CEREBRAL ANEURYSM: A CASE REPORT
}

\author{
Arsida BAJRAMI*, Batuhan KARA**, Hatem Hakan SELÇUK**, Beyza ARSLAN*, \\ Murat ÇABALAR*, Vildan Ayse YAYLA* \\ * Bakurköy Dr. Sadi Konuk Training and Research Hospital, Department of Neurology, ÍSTANBUL, TURKEY \\ ** Bakırköy Dr. Sadi Konuk Training and Research Hospital, Department of Radiology, ÍSTANBUL, TURKEY
}

\begin{abstract}
Hypertrophic olivary degeneration (HOD) is a degenerative disorder of the inferior olivary nucleus (ION) that occurs after damage to the dentatorubroolivary pathway (DROP). Damage to the DROP causes hypertrophy and enlargement of the inferior olivary nuclei (ION) contrary to the atrophy observed in the other parts of central nervous system. Focal lesions that may lead to HOD include ischemia, hemorrhage, trauma, and cavernous hemangioma and it also may mimic diseases including tumors and demyelinating processes. We here in present our experience with a case of bilateral HOD, which was a result of a thromboembolic complication during endovascular aneurysm embolization.
\end{abstract}

Key Words: Hypertrophic olivary degeneration, dentatorubroolivary pathway, thromboembolic, endovascular.

\section{INTRASEREBRAL ANEVRIZMANIN ENDOVASKULER TEDAVI SONRASI GELIŞEN İSKEMIYE İKINCIL OLARAK GELIŞEN BILLATERAL HIPERTROFIK OLIVAR DEJENERASYON: OLGU SUNUMU}

ÖZET

Hipertrofik olivar dejenerasyon (HOD) inferior olivar nukleusun dentatorubro-olivar yolakta (DROP) oluşan herhangi bir hasara yanıt olarak oluşan trans-sinaptik dejenerasyon türüdür. Santral sinir sisteminde bir anatomik bölgenin dejenerasyona sekonder gelişen nöron kaybı ve glial hücrelerinde çoğalmanın aksine DROP yolağında transnöronal dejenerasyon sonucu hipertrofi gelişmektedir. HOD, tümör ve demyelinizan hastalıklar dahil pek çok patolojiyi taklit edebilen, iskemi, kanama, travma ve kavernöz hemanjioma bağlı gelişen, göreceli olarak nadir rastlanan bir durumdur. Endovasküler anevrizma embolizasyonu sırasında tromboembolik komplikasyon sonucu gelişen, bilateral HOD olgusuyla deneyimimizi paylaşmaya amaçladık.

Anahtar Sözcükler: Hipertrofik olivar dejenerasyon, dentatorubro-olivar yolak, tromboembolik, endovaskuler.

\section{INTRODUCTION}

Hypertrophic olivary degeneration (HOD) is a degenerative disorder of the inferior olivary nucleus (ION) that occurs after damage to the dentatorubroolivary pathway (DROP) (also called the Guillain-Mollaret triangle, or GMT). Damage to the DROP causes hypertrophy and enlargement of the inferior olivary nuclei (ION) contrary to the atrophy observed in the other parts of central nervous system. The magnetic resonance imaging features shows typical radiological temporal course that correlates with histopathological findings (1).
Bilateral involvement is extremely rare. Clinically, the patient may present with palatal tremor, dentorubral tremor and features of cerebellar/brainstem dysfunction. (2,3) Focal lesions that may lead to HOD include ischemia, hemorrhage, trauma, and cavernous hemangioma and it also may mimic diseases including tumors and demyelinating processes. We here in present our experience with a case of bilateral HOD, which was a result of a thromboembolic complication during endovascular aneurysm embolization.

\footnotetext{
Corresponding author: Arsida Bajrami, MD. Bakırköy Dr. Sadi Konuk Training and Research Hospital, Department of Neurology, İstanbul, Turkey. Phone: +902124147133 E-mail: arsidabajrami@gmail.com Received: $29.12 .2015 \quad$ Accepted: 16.05.2016

This article should be cited as following: Bajrami A, Kara B, Selçuk H. H, Arslan B, Cabalar M, Yayla V. A. Bilateral hypertrophic olivary degeneration secondary to ischemia following endovascular treatment of cerebral aneurysm: A case report. Turkish Journal of Cerebrovascular Diseases 2016; 22 (3): 133135. doi:10.5505/tbdhd.2016.60362
} 


\section{CASE}

A 60-year-old male was admitted to our emergency department with sudden onset of headache and blurred vision. His medical history was unremarkable. Non-enhanced brain tomography revealed an aneurysmatic dilatation located in right ambient cistern. Digital subtraction angiography showed a wide-necked right superior cerebellar artery aneurysm. The patient was treated with stent-assisted coil embolization (Figure I). The procedure was completed and the patient recovered with left facial paralysis and left hemiparesis. Diffusion-weighted imaging immediately after procedure showed an acute ischemia in the posterior aspect of right cerebral peduncle and superior cerebellar peduncle, caused by thromboembolic occlusion of a perforating artery arising from stented proximal right posterior cerebral artery (Figure II). Two months after initial insult, in his routine control visits, T2weighted MR images showed enlargement and increased signal intensity in both olivary nuclei, consistent with bilateral HOD (Figure III). Still his clinical examination was unremarkable, except for dizziness responsive to symptomatic treatment.

\section{DISCUSSION}

The anatomical triangle named after Guillain and Mollaret, first described in 1931, consists of the ipsilateral red nucleus, the inferior olivary nucleus and the contralateral dentate nucleus (4). Anatomically the edges of the triangle include the connection between superior cerebellar peduncle to ipsilateral red and the contralateral dentate nuclei and the other connection of inferior cerebellar peduncle to contralateral dentate and the ipsilateral and inferior olivary nuclei. While hypertrophic olivary degeneration can be caused by any lesion involving the aforementioned structures, it is typically seen with focal lesions that disrupt the afferent pathways to the olive (dentatorubral and rubro-olivary pathways).

HOD is almost always unilateral; however, rare bilateral cases have been reported. Midline lesions or lesions in the brachium conjunctivum (superior cerebellar peduncle), finally interrupting decussation of the DROP, can result in bilateral HOD. In CNS, transneuronal degeneration associated with atrophy of the targeted structure is a common response to a confined lesion. Still transneuronal degeneration resulting in

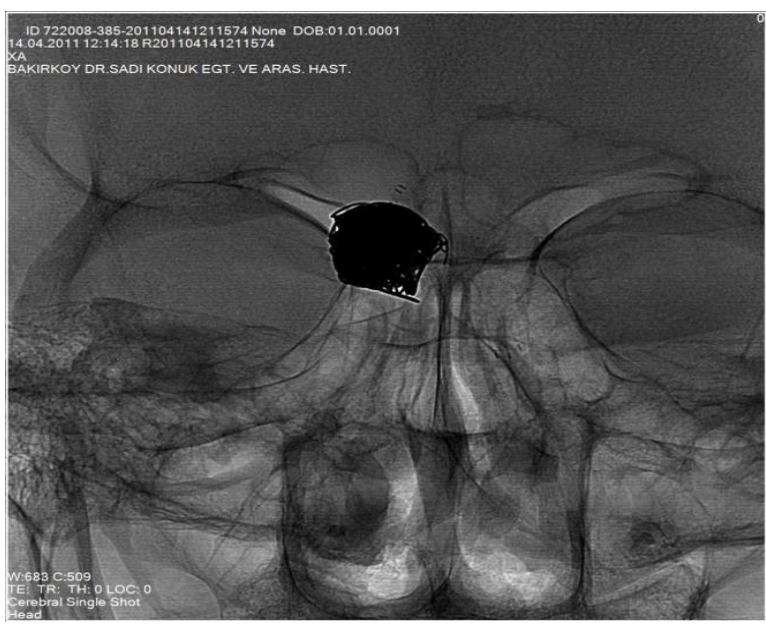

Figure I. PA view shows appied intracranial stent and coil mesh.

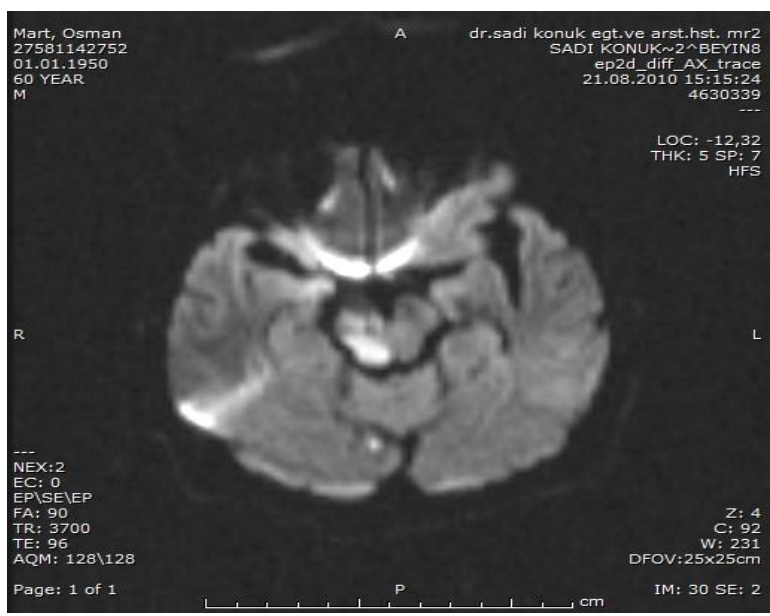

Figure II. Acute ischemia in the posterior aspect of the right cerebral peduncle and superior cerebellar peduncle on diffusion-weighted imaging.

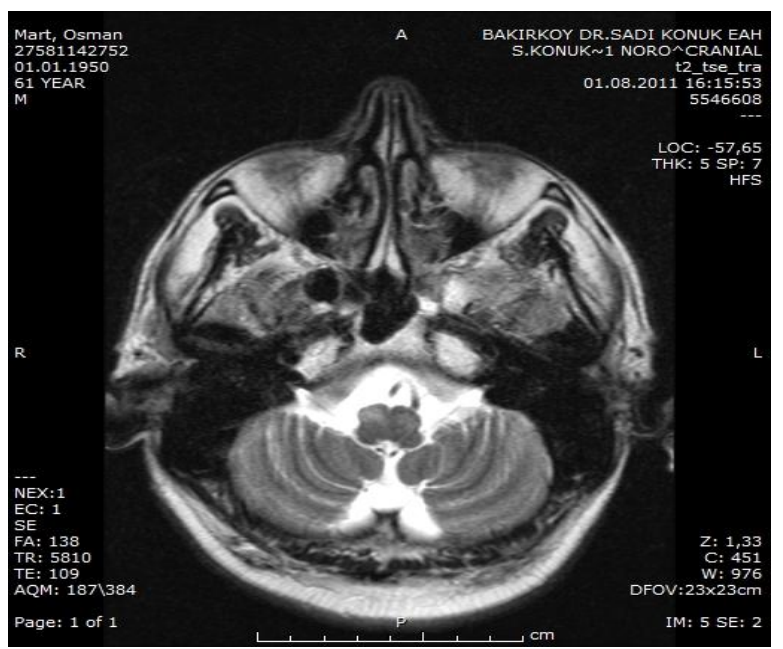

Figure III. Axial T2 image at the level of bulbus shows bilateral hypertrophy of olivary nuclei and increased signal intensity. 
hypertrophy of the targeted region is unique to the inferior olivary nucleus (5). Pathologic changes including vacuolar degeneration, neuronal enlargement, astrocyte hypertrophy, demyelination, and gliosis are reflected in the typical imaging appearance of HOD, with an increase in signal on $\mathrm{T} 2$ and proton density weighted images and an increase in size of the olivary nucleus (6).

Depending on the time interval between the event and the scanning procedure, the size of the hypertrophic olivary nucleus is variable, with a normal size in the acute stage. Olivary hypertrophy typically develops around six months after the event and resolves after three to four years. Radiologycally, an increased signal on T2 and proton density images confined to the olivary nucleus or nuclei (with or without ION enlargement) with lack of contrast enhancement or diffusion restriction typically appears early (around one month after the initial lesion) and persists infinitely (1, 7). Three stages of hypertrophic olivary degeneration can be seen on T2 weighted MR WMR images. In the first stage occurring within the first 6 months, only hyperintensity of the inferior olivary nucleus is seen. The second phase lasts from 6 months up till 3 to 4 years, and is characterized by an increase in size and intensity with non-visualization of the pre- and post-olivary sulci. The third stage begins with the resolution of the hypertrophy with persistence of the hyperintense signal in the olivary nucleus, which may last indefinitely (7).

The clinical appearance of the hallmark symptoms which consist of palatal myoclonus and other involuntary movements (dentatorubral tremor, ocular myoclonus and cerebellar or brainstem dysfunction) persists despite the resolution of the imaging charecteristics of HOD. These symptoms presumably reflect loss of inhibitory control that is transmitted through dentat-rubral pathway (8). The differential diagnosis of signal hyperintensity n T2 weighted images within the pontomedullary region includes tumors, demyelinating lesions, infarction, and inflammatory processes (tuberculosis, sarcoidosis, or encephalitis). The lack of contrast enhancement, however, is contrary to many tumorous entities or an infectious origin, while the additional enlargement of the olivary nucleus is contrary to chronic stages of infarction or multiple sclerosis. MRI fiber tractography also can demonstrate disruption of the triangle of Guillain-Mollaret and can be useful in the diagnosis of HOD when findings on conventional MRI imaging are equivocal (9). Dincer et al., apart from documenting disruptions in the triangle of Guillain-Mollaret in HOD, showed increase in radial and axial diffusivity in the inferior olives, representing demyelination and neuronal hypertrophy, respectively (10).

In conclusion, diagnosis of HOD should be considered in a patient with dento-rubroolivary pathway lesions. The bilateral HOD is extremely rare and it is also important to differentiate between HOD and other medullary lesions. Familiarity with the clinical and radiological findings, which are very characteristic, is crucial and would avoid unnecessary diagnostic tests.

\section{REFERENCES}

1. Goyal M, Versnick E, Tuite P, et al. Hypertrophic olivary degeneration: Metaanalysis of the temporal evolution of MR findings. Am J Neuroradiol 2000;21:1073-7.

2. Sameer V, Anuj P, Ajan K, et al Bilateral hypertrophic olivary degeneration. Ann Indian Acad Neurol. 2013 JulSep; 16(3): 404-405.

3. Lim CC, Lim SAN et al, Images in clinical medicine. Pendular nystagmus and palatomyoclonus from hypertrophic olivary degeneration. Engl J Med. 2009 Feb 26; 360(9):e12

4. Guillain G, Mollaret P. Deux cas de myoclonies synchones et rhythms velopharyngo-laryngo-oculo-diaphragmatiques. Rev Neurol 1931;545-66.

5. Kitajima M, Korogi Y, Shimomura 0, et al. Hypertrophic olivary degeneration: MR imaging and pathologic findings. Radiology 1994;192:539-43.

6. Goto N, Kaneko M. Olivary enlargement: chronological and morphometric analyses. Acta Neuropathol 1981;54:27582.

7. Vattoth S, Ahmed F.Y, Telford R.C et al, Hypertrophic Olivary Degeneration: Review of Anatomy, Pathology, and Imaging. Neurographics 2014; 4:114-122.

8. Deuschl G, Toro C, Valls-Sole J, et al. Symptomatic and essential palatal tremor. 1. Clinical, physiological and MRI analysis. Brain 1994;117:775-88.

9. Shah R, Markert J, Bag AK, Curé JK. Diffusion tensor imaging in hypertrophic olivary degeneration. AJNR Am J Neuroradiol 2010;31;1729-31.

10. Dinçer A, Özyurt O, Kaya D, Koaa E, Öztürk C, Erzen C, et al. Diffusion tensor imaging of Guillain-Mollaret triangle in patients with hypertrophic olivary degeneration. J Neuroimaging 2011;21:145-51. 